\title{
Gestão de Pessoas em Empresas Turísticas de Pequeno Porte: o caso do setor hoteleiro
}

\author{
Human Resources Management in Small Tourism \\ Enterprises: the case of the hospitality sector
}

Rivanda Meira Teixeira ${ }^{1}$

\begin{abstract}
RESUMO: A gestão de pessoas no setor de turismo assume dimensão estratégica para as empresas, visto a necessidade de atrair, desenvolver e manter pessoas qualificadas para atender às necessidades dos clientes. Este estudo teve por objetivo analisar as práticas, a demanda de profissionais e os desafios na gestão de pessoas nas empresas hoteleiras de pequeno porte. Entrevistas pessoais foram realizadas com 30 proprietários/gerentes de estabelecimentos hoteleiros de pequeno porte, localizados em Aracaju e nos principais municípios turísticos do Estado de Sergipe. A baixa escolaridade dos empregados foi percebida como o maior desafio da gestão de pessoas nas empresas de pequeno porte do setor hoteleiro, pois essa limitação se reflete em todos os demais aspectos, a exemplo das dificuldades dos empregados em absorver novos conhecimentos e melhorar a qualidade dos serviços prestados.
\end{abstract}

PALAVRAS-CHAVE: gestão de pessoas; pequenas empresas; setor hoteleiro.

ABSTRACT: Human resources management in the tourism sector plays a strategic role for enterprises, due the need to attract, develop and keep

1. Doutora em Administraçāo pela Cranfield University, Inglaterra, com pós-doutorado em Turismo pela Bournemouth University, Inglaterra, e em Gerenciamento de Pequenas Empresas do Setor Turístico pela Strathclyde University, Escócia; professora adjunta do Departamento de Administraçāo Geral e Aplicada da UfPr. Contato: Universidade Federal do Paraná / Departamento de Administraçāo Geral e Aplicada - Rua Prefeito Lothario Meissner, 3.400 - 3a andar - Campus III - 80210-170 Curitiba-PR; e-mail: rivandateixeira@terra.com.br. 
qualified people to answer client's needs. This study has the objective to analyse management practices, professional demand and challenges in people management in small hospitality enterprises. Personal interviews were conducted with 30 business owners/managers of small enterprises located in Aracaju and in tourism towns in Sergipe State. Employees' low level of formal education was perceived as the major challenge that these companies have to face in relation to human resources management because this limitation is reflected in many other aspects, as for instance the difficulty to acquire new knowledge and of improving services quality.

KEYWORDS: human resources management; small enterprises; hospitality sector.

\section{Introdução}

Para serem competitivas, as organizaçōes devem se tornar mais flexíveis, inovadoras, voltadas para a qualidade, para os consumidores, buscando constantemente melhorar seu desempenho. Essa perspectiva implica novas maneiras de trabalhar, novos papéis, novos relacionamentos e habilidades, estimulando a necessidade do desenvolvimento dos recursos humanos. Como destacam Bohlander, Snell e Sherman (2003: 2), "embora as pessoas tenham sido sempre fundamentais no ambiente empresarial, hoje elas desempenham um papel ainda mais central para a obtenção de vantagem competitiva de uma empresa".

Percebida por Longenecker, Moore e Petty (1997) como contingencial e situacional, a área de recursos humanos - RH depende da cultura, da estrutura organizacional adotada e, mais ainda, das características do contexto ambiental, do negócio predominante da organizaçāo, das suas características internas, das funçōes e dos processos pelos quais responde, e de inúmeras outras variáveis importantes. De acordo com esses autores, o profissional especializado em gestão de RH é encontrado principalmente nas grandes organizaçōes - e excepcionalmente nas médias. No entanto, afirmam os referidos autores que as atividades de gerenciamento de pessoas existem em qualquer tipo de organizaçāo, nāo importando seu tamanho. Destacam, ainda, Longenecker, Moore e Petty (1997:446) que, "tendo em vista as características especiais do emprego, associadas com o pequeno porte, o empreendedor precisa desenvolver um programa de recursos humanos que seja diretamente aplicável a uma pequena empresa".

Quando se trata da gestāo de pessoas no setor turístico, de acordo com Baum (1999), o denominador comum de todos os negócios de grande e pequeno porte é a sua dependência de pessoas qualificadas para vender os produtos e serviços para um consumidor cada vez mais exigente. Com a tecnologia e a capacidade das comunicaçōes de distribuir padrōes de produtos em nível global, o setor de turismo necessita de serviços de qualidade para alcançar vantagens competitivas. Afirma o autor que, para alcançar esse estágio, são necessários investimentos em todas as funçōes de gerência de recursos humanos, como recrutamento, seleçāo, treinamento e desenvolvimento contínuo.

O presente estudo foi motivado por esse contexto e pela constatação da existência de um reduzido número de estudos, no Brasil, voltados para o gerenciamento de pessoas em empresas do setor hoteleiro - e ainda em menor número voltados para as empresas de pequeno porte. Este artigo tem por objetivo analisar as práticas e os desafios na gestão de pessoas nas empresas hoteleiras de pequeno porte e espera contribuir para aumentar os conhecimentos sobre a gestāo dessas empresas, de modo que sejam mais adequados às suas necessidades.

\section{Estudos publicados em gestão de pessoas}

\section{Pequenas empresas}

Apesar de ser área de estudos relativamente consolidada no Brasil, pode-se constatar que ainda são escassos os estudos que abordam a gestāo de pessoas nas empresas de pequeno porte no país. O SEBRAE (1993), ao realizar estudos sobre indicadores de competitividade nas micro e pequenas indústrias em uma amostra de 1.057 empresas, abordou algumas práticas de RH, tais como formas de seleção, treinamento, remuneraçāo, benefícios oferecidos e rotatividade de mão-de-obra. Também realizou uma série de pesquisas com micro e pequenas empresas dos setores industrial, comercial e de serviços chamada SONDAGEM, que tratou de tópicos como qualidade de vida no trabalho e situaçāo do menor no mercado de trabalho.

Em levantamento realizado por Lima (2000) sobre artigos que abordam as pequenas e microempresas no Brasil, foram encontrados apenas três estudos que se voltam para a gestão de RH nessas empresas: o de Barbosa (1991), o de Teixeira (1996) e o de Teixeira, Andrade Júnior e Banganga (1998). Essa revisāo foi feita com base em artigos publicados em periódicos na área de administração de empresas e nos anais dos Encontros Anuais da Associação Nacional de Pós-Graduação em Administraçāo (ENANPAD) relativos ao período 1980-2000. Nos anais do ENANPAD dos anos de 2001 e 2002 não foram encontrados artigos que tratassem especificamente do tema, porém Reis e Escrivão Filho abordaram em 2003 o treinamento na pequena empresa. 
Barbosa (1993) abordou os conflitos nos recursos humanos, em pequenas e médias empresas do setor de autopeças, na região de Contagem e Belo Horizonte. Constatou que os conflitos existentes deviam-se, sobretudo, a questões salariais, porém os empregados preferiam trabalhar nesse tipo de empresas. Por sua vez, o estudo de Teixeira (1996) foi objeto de tese de doutoramento e teve como principal objetivo analisar a responsabilidade social das pequenas empresas com relação aos seus empregados. Foram realizadas 55 entrevistas abertas com empregados e donos de pequenas empresas sergipanas, adotando-se uma abordagem não-positivista. Uma definição operacional de "responsabilidade social" foi elaborada para que pudesse ser aplicada à realidade das pequenas empresas. O estudo abordou questões legais nas relações de trabalho, salários, higiene e segurança ocupacional, estabilidade no emprego, benefícios, desenvolvimento do empregado (conteúdo do trabalho, promoção e treinamento), oportunidade de trabalho para menores, deficientes físicos, discriminação contra mulheres e negros, além do relacionamento entre donos e empregados. Os resultados levaram ao desenvolvimento de tipologias de responsabilidade social em que as empresas se encontram no contexto de um país subdesenvolvido. Finalmente, oestudo de Teixeira, Andrade Junior e Banganga (1999) teve como objetivo identificar as práticas adotadas no gerenciamento dos recursos humanos em pequenas e médias empresas industriais, enfocando aspectos tradicionais de RH, tais como recrutamento e seleção, treinamento, rotatividade de mão-de-obra, promoção, política salarial e qualificação de empregados. Outros tópicos, porém, que fazem parte da agenda atual de $\mathrm{RH}$, foram acrescentados: benefícios, higiene e segurança ocupacional, relações sindicais e trabalhistas, discriminação racial e sexual, oportunidades para emprego de menores e deficientes físicos, e relacionamento entre patrão e empregados. $\mathrm{O}$ estudo concluiu que, de maneira geral, as PME's se limitavam a fazer o controle burocrático das atividades de pessoal e, além de não se modernizarem nas suas práticas gerenciais, não incorporaram as novas técnicas e atitudes que fazem parte das atuais preocupações de RH nos anos 1990.

O mais recente dos estudos do ENANPAD, o de Reis e Escrivão Filho (2003), analisou as barreiras que limitam a prática do treinamento na pequena empresa. Concluiu que muito pouco se conhece a respeito das práticas de recursos humanos e da função de treinamento. Com o uso da metodologia de multicasos exploratório e descritivo foram estudadas quatro empresas do ramo metal-mecânico da cidade de São Carlos (SP), sendo duas de base tecnológica e duas de tecnologia convencional. Como principais resultados e contribuições, a pesquisa apontou as barreiras para a aplicação do treinamento na pequena empresa, e também a identificação dos fatores que influenciam ou condicionam a necessidade, a natureza e o processo das ações de treinamento na pequena empresa.
O tema gestão de pessoas em empresas de pequeno porte, apesar de sua relevância, também foi pouco abordado nos Encontros sobre Empreendedorismo e Gestão de Pequenas Empresas (EGEPE I, II e III), pois apenas três trabalhos foram identificados. Paim et al. (2001) analisaram as estratégias de gestão de RH em três empresas de agronegócio no Rio Grande do Sul, e a partir de dados coletados em fontes documentais, formulários e entrevistas realizadas com profissionais do setor, concluíram que a estratégia adotada por essas empresas é tradicional, especialmente no que se refere a políticas de treinamento e desenvolvimento, remuneração e benefícios, comunicação e relações sindicais. Udenal e Gimenez (2001), por sua vez, procuraram identificar como empresas do ramo de confecções e vestuário estão aproveitando o potencial criativo dos seus colaboradores para atuar competitivamente no mercado. Verificaram os pesquisadores que a criatividade dos funcionários é aproveitada pelas empresas apenas como sugestões para a solução de problemas e que ocorrem de forma espontânea. Concluiu também que não existe qualquer ação planejada para incentivar essa criatividade, apesar da importância atribuída a ela pelos seus proprietários. Finalmente, o estudo de Pizolotto (2003) tratou da gestão de pessoas em indústrias de transformação da Região do Médio-Alto Uruguai do Rio Grande do Sul, e concluiu que a pouca incidência de práticas de gestão de pessoas, com base nos modelos teóricos, convidam os seus gestores a repensar essas formas de atuação, predominantes em suas organizações.

Estudo sobre o tema foi também identificado no Balas em 2002, de autoria de Teixeira e Barbosa (2002), realizado em quarenta pequenas e médias indústrias sergipanas. Concluiu a pesquisa que, em função da oferta excessiva de mãode-obra desqualificada no Estado e por usarem tecnologias pouco sofisticadas, os seus empresários praticamente não valorizam ou investem nos seus recursos humanos. Destacaram, ainda, as autoras, que essa postura traz certa apreensão com relação ao futuro dessas empresas, pois, em assim agindo, não se preparam para oferecer aos seus clientes produtos de qualidade e para enfrentar a concorrência, que tende cada vez mais a se acirrar dentro de uma nova perspectiva de mercado.

\section{Setor hoteleiro}

Ao analisar a gestão de pessoas em empresas do setor hoteleiro, Knowles (1998) iniciou afirmando que não importava se o hotel era de pequeno, médio ou grande porte: os empregados necessitarão sempre de uma variedade de habilidadestécnicas e comportamentais que os permita atuar eficientemente. Para Nickson (1999), apesar da retórica dos empresários de que as pessoas são os seus maiores 
patrimônios, muitos autores permanecem convencidos de que essa evidência não corresponde à prática das ações na indústria hoteleira. Para esse autor, a referida indústria continua a ser vista como insatisfatória, com relação às suas práticas de gerenciamento de RH. O relatório realizado pelo Department of National Heritage, em 1996, no Reino Unido, mostrou que existem dificuldades de recrutamento, carência de mão-de-obra qualificada, relativamente baixos salários, alta rotatividade e setor pouco atrativo para empregos. Além disso, segundo a pesquisa do Institute of Personnel and Development, realizada em 1997 naquele país, os setores hoteleiro e de lazer possuem o maior índice de rotatividade, quando comparados a outros 20 setores, alcançando a taxa de 34,56\% (Nickson, 1999).

Baum (1999) defendeu a posição de que o Estado tem de se envolver na área de turismo, especialmente no desenvolvimento de pessoas. Argumentou que, apesar da crescente importância das organizações de grande porte nesse setor, ele ainda é dominado por médias e pequenas empresas. Essas empresas têm maiores dificuldades na gerência de recursos humanos em função, principalmente, da carência de mão-de-obra especializada e qualificada. Outro argumento defendido pelo autor para o envolvimento do Estado na área de turismo é que, no contexto de economias de países subdesenwolvidos, esse setor ainda não possui o nível de maturidade necessário e de qualificação de mão-de-obra. Particularmente, a ausência de um setor privado forte justifica a necessidade do governo de investir na capacitação de pessoas. No nível prático, educação para o turismo mais treinamento e desenvolvimento de habilidades são atividades relativamente maduras em países desenvolvidos, e em evolução em comunidades e países onde o turismo e a hotelaria são relativamente recentes.

Vários estudos tratam da gestão de RH em hotelaria fora do Brasil, e alguns deles merecem destaque especial. O estudo de Anastassova e Purcell (1995), realizado em hotéis da Bulgária, analisa as práticas de gerenciamento de pessoas e estilos gerenciais, considerando as mudanças das relações de trabalho que estão sendo adotadas por essas empresas dentro da perspectiva da economia de mercado. Já o estudo comparativo realizado em hotéis na Austrália e Singapura por Cheng e Brown (1998) aponta as estratégias de $\mathrm{RH}$ utilizadas para diminuir a rotatividade de empregados nesses dois países, e demonstra que existe influência positiva entre a utilização de técnicas de recrutamento, seleção e do processo de indução para diminuir os índices de rotatividade. A pesquisa realizada por McGunnigle e Jameson (2000) com dez dos 50 maiores hotéis do Reino Unido, cada um com média de 85 empregados, procurou estabelecer relacionamentos entre o gerenciamento de $\mathrm{RH}$ e o comprometimento dos empregados, com ênfase nas práticas de recrutamento e seleção, treinamento e desenvolvimento. Por sua vez, o Conselho de Educação Gerencial para Hospitalidade do Reino Unido patrocinou estudo sobre a análise do custo-benefício do treinamento e o seu impacto no desempenho dos negócios (Eaglen, Lashley \& Thomas, 1999). O objetivo foi propor um modelo que identificasse os principais benefícios e custos do treinamento, tendo sido aplicado em 12 restaurantes da cadeia McDonalds para fins de teste.

Pesquisa nacional realizada em pequenos negócios do Reino Unido no setor de turismo e hospitalidade voltou-se para a análise da demanda de habilidades e práticas de treinamento (Thomas et al., 2000), e tem relação direta com o presente estudo. Essa survey foi realizada por meio de questionários pelo correio, que foram respondidos por 1.394 empresas de pequeno porte, sendo $38,7 \%$ delas do setor hotcleiro. Além de enfocar práticas de recrutamento, seleção e rotatividade, voltou-se com maior detalhe para a análise das habilidades dos empregados, treinamento, emprego para graduados e novas possibilidades de empregos. Dentre os resultados, evidenciou-se que cerca de dois terços das empresas pesquisadas estavam satisfeitas com o nível de qualificação de seus empregados. No entanto, as empresas de maior porte identificaram um maior número de deficiências (gaps) em sua mão-de-obra. Dentre esses gaps destacam-se os cuidados com os clientes, conhecimentos de informática e consciência comercial. Embora estratégias de treinamento formal não sejam comuns nessas empresas, mais de um quarto delas informou possuir um plano de treinamento informal.

No Brasil são poucos os estudos que tratam da gestão do setor turístico e, em muito menor número, os que abordam especificamente a gestão de pessoas. Em 1982, Araújo, Mendes e Enders realizaram um estudo sobre as percepções e avaliações dos turistas sobre os recursos humanos que trabalham diretamente nos serviços e equipamentos turísticos de Natal, Rio Grande do Norte, comparando-as com as demais capitais do Nordeste. Foram analisadas características como eficiência, hospitalidade e aparência dos recepcionistas de hotéis, funcionários de transportadoras e de agências, guias, garçons, vendedores de loja de artesanato, motoristas de táxi e guardas de trânsito. Observou-se que, apesar de o tema ser pouco abordado nos estudos sobre turismo, os próprios turistas reconhecem os recursos humanos como elemento indispensável para a qualidade dos serviços. Identificou-se que o desempenho do pessoal de Natal é, de modo geral, favorável, em comparação a outras capitais nordestinas.

Estudo realizado por Aquino (1994) analisou o processo de atração de recursos humanos por parte das pequenas e médias empresas hoteleiras na cidade de Fortaleza, com concentração nas áreas de hospedagem e alimentação. Destacou-se que, embora haja um reconhecimento da existência das funções de recrutamento e seleção nessas empresas, sua utilização é insipiente. Em 2000, Dias realizou um estudo de caso no complexo turístico do Beach Park, em Fortaleza, analisando qual o valor do capital humano para o sucesso da empresa, e concluiu 
que $70 \%$ dos gerentes entrevistados responderam não existir preocupação em manter, ou melhor, em conservar seu capital humano. A empresa vê a rotatividade de seus funcionários como um fato que pouco abala suas estruturas externas. Outro resultado que chamou a atenção é que, apesar de os gerentes afirmarem que os funcionários conhecem suas atividades, serviços, missão e políticas das empresas, $72 \%$ contestaram e disseram que não os conhecem. Dias chegou à conclusão de que não existe correlação entre a gestão do capital humano e o sucesso da organização.

Barbosa e Oliveira (2002) analisaram se a gestão de recursos em um hotel de grande porte na cidade de Recife contribui para alcançar a qualidade na prestação dos serviços. Para tanto, utilizaram o método de análise de conteúdo, tendo como referencial teórico a gestão de recursos humanos e o marketing interno, que forneceram suporte à análise de dados. Como resultado, o estudo revelou que a gestão de recursos humanos praticada pelo hotel apresentava-se consistente e bem estruturada, o que possibilitava despertar e desenvolver, nos colaboradores, um sentido de compromisso com a qualidade dos serviços. Por sua vez, Gueiros e Oliveira (2002) realizaram pesquisa do tipo exploratório-descritiva, com o objetivo de apresentar resultados relativos à satisfação dos funcionários de hotéis do Grande Recife com as políticas de RH e, entre estas, as referentes à qualidade de vida no trabalho. A amostra foi intencional, não-probabilística, escolhida de acordo com acessibilidade, localização e adequação dos hotéis aos objetivos do estudo. Os hotéis pesquisados apresentaram níveis consideráveis de satisfação dos empregados em relação a essas políticas, tais como: transparência das informações; ambiente físico de trabalho; relacionamento com colegas, com as chefias e com a área de $\mathrm{RH}$, além de sistema de segurança e saúde.

O único estudo que se voltou especificamente para a gestão de RH em pequenas empresas hoteleiras foi produzido por Silva e Barbosa em 2002. Foi realizado em hotel de pequeno porte na cidade de Recife e investigou como o processo de treinamento pode colaborar para a implantação de um sistema de padronização dos serviços. Os resultados demonstraram que o programa de treinamento propiciou o estímulo à criação de uma cultura voltada para o aprendizado de técnicas operacionais e o sentido de qualidade na prestação dos serviços, além de estabilização nos custos de operação, diminuição nos acidentes de trabalho e menor índice de reclamações de clientes.

\section{Aspectos metodológicos}

Este estudo tem por objetivo analisar as práticas de gestão, identificar as necessidades de mão-de-obra e os desafios na gestão de pessoas em empreendi- mentos do setor hoteleiro de pequeno porte, cujas empresas são geralmente gerenciadas por seus proprietários. Para a coleta de dados foi realizado um levantamento com a utilização da técnica de entrevistas pessoais, e pretendeu-se, com a utilização desse método, captar as percepções dos entrevistados a respeito do tema, especialmente dos aspectos relacionados às variáveis qualitativas. Wright (1996) destacou as vantagens da entrevista pessoal em estudos que envolvam aspectos que impliquem explicações mais detalhadas de um determinado fenômeno, e que se ofereçam garantias de confidencialidade para os entrevistados. Foi aplicado um questionário estruturado, composto de 21 questões fechadas e abertas, a fim de obter respostas às perguntas da pesquisa (Anexo I).

De acordo com o World Travel Organization - wTO (2000), são considerados micro e pequenos estabelecimentos hoteleiros os que possuem menos de 50 quartos e que empregam menos de dez pessoas. No entanto, o critério do número de empregados adotado pelo wTo parece adequado aos países desenvolvidos, onde o custo da mão-de-obra é muito mais alto que nos subdesenvolvidos. No Brasil, apesar de ser, às vezes, utilizado por alguns autores, a exemplo de Duarte (1996), o número de unidades habitacionais para a definição do tamanho, não existem critérios formais para essa definição. No entanto, como essas empresas são do setor de serviços, adotou-se, neste estudo, a definição do Serviço Brasileiro de Apoio às Micro e Pequenas Empresas - SEBRAE (2003), na qual são consideradas micro as que possuem até nove empregados; de pequeno porte, as que possuem de dez a 49 empregados; de médio, as que possuem de 50 a 99 empregados, e grande, as que possuem mais de 99 empregados.

Com base em dados do Plano de Desenvolvimento Integrado do Turismo Sustentável para o Pólo Costa dos Coqueirais (2001), existiam 88 hotéis e pousadas classificados e não-classificados em Sergipe. Para este estudo foi considerada uma amostra de 30 estabelecimentos localizados em Aracaju, capital do Estado, e nos municípios que possuem maior movimento turístico, a exemplo de Itabaiana, Lagarto, Estância, Tobias Barreto e Canindé do São Francisco. O critério de amostragem adotado foi o não-probalibístico por julgamento. As empresas pesquisadas foram selecionadas em função da variável tamanho, pois para este estudo foram considerados somente os hotéis de pequeno porte e as pousadas que possuíssem até 49 empregados.

Vale destacar as limitações do estudo, como, por exemplo, as inerentes ao método, que se baseia na ênfase aos aspectos perceptivos, os quais, além disso, são oriundos de apenas uma fonte, os empresários. Outra limitação relaciona-se à adoção de critério amostral não-probabilístico, por meio do qual o pesquisador depende da adesão dos entrevistados, não possibilitando qualquer tipo de generalização, não se admitindo que estes possam, de alguma forma, representar o universo. 


\section{A gestão de pessoas em empresas de pequeno porte: um estudo no setor hoteleiro}

A gestão de pessoas nas empresas de pequeno porte do setor hoteleiro em Sergipe foi analisada, neste estudo, por meio dos seguintes indicadores: (a) relacionados às práticas de gestão analisadas através dos salários, escolaridade, recrutamento, seleção e treinamento, benefícios e rotatividade; (b) relacionados à demanda de profissionais analisados através de indicadores, como a identificação dos profissionais que se pretende contratar, dos requisitos e habilidades necessários para a contratação, da identificação dos profissionais difíceis de encontrar no mercado, das maiores deficiências dos empregados e da contratação de graduados e de estagiários; e, finalmente, (c) os maiores desafios de pessoal enfrentados por essas empresas.

\section{Salários}

A grande maioria dos profissionais que trabalhava nessas empresas, como camareiros, copeiros, auxiliares de serviços gerais, lavadeiras e mensageiros, recebia basicamente um salário mínimo (SM) ou um pouco mais, chegando, no máximo, a dois. Outros profissionais, como recepcionistas, assistentes administrativos, governantas, cozinheiros e garçons ganhavam, geralmente, na faixa de um e meio SM, podendo até chegar a quatro SM se exercessem funções de supervisão ou se o empreendimento fosse de maior porte. Gerentes e supervisores poderiam alcançar, nesses estabelecimentos, um patamar máximo de até dez SM em hotéis de maior estrutura, com quase 50 empregados. Foi mencionado, em algumas empresas, que, para recepcionistas ou gerentes, haveria um porcentual flexível a ser incorporado, em função do desempenho das vendas. Em uma empresa foi citado o rateio da taxa de serviço, baseado em um sistema de pontos.

\section{Escolaridade}

A grande maioria dos recepcionistas que atuava nessas empresas tinha o segundo grau completo ou incompleto, mas cerca de 36,6\% delas informaram contratar, para a sua recepção, pessoas com escolaridade de primeiro grau, apenas. Para os níveis de supervisão e gerência, a grande maioria dos profissionais possuía o segundo grau, mas foram encontradas pessoas cursando o nível superior ou o curso seqüencial de dois anos na área de turismo.
Para os que atuavam como copeiros, camareiras, cozinheiros, lavadeiras ou em serviços gerais, observou-se que o nível de escolaridade predominante era o primeiro grau, mas foram encontradas, em $26,6 \%$ dessas empresas, pessoas analfabetas ou semi-analfabetas, assim consideradas as que sabiam basicamente escrever o nome. Esses resultados permitiram inferir que o nível de escolaridade dos profissionais do setor é muito baixo, e que tais dados são coerentes com os salários pagos, em média também muito reduzidos. Vale lembrar as implicações diretas da falta de escolaridade na qualidade de serviços prestados por essas empresas.

\section{Recrutamento e seleção}

As empresas mencionaram que utilizam múltiplas formas de recrutamento de empregados, merecendo destaque a busca de informações por meio de amigos, os dados do cadastro e através dos empregados (Tabela 1). Outras formas foram citadas, como por intermédio da imprensa escrita e falada, do NAT (Núcleo de Apoio ao Trabalhador), do SENAC, através de agências e na porta.

Tabela 1. Formas de recrutamento

\begin{tabular}{|l|c|c|}
\hline Formas & Freqüência absoluta* $^{*}$ & Freqüência relativa** $^{*}$ \\
\hline Amigos & 17 & 56,6 \\
\hline Cadastro & 16 & 53,3 \\
\hline Empregados & 15 & 50,0 \\
\hline Jornal e rádio & 6 & 20,0 \\
\hline NAT & 5 & 16,6 \\
\hline Agências/SENAC & 5 & 16,6 \\
\hline Porta & 1 & 5,5 \\
\hline Total de respostas & 65 & 100,0 \\
\hline Total de respondentes & 30 & \\
\hline
\end{tabular}

* A questão adnitiu mais de uma resposta.

${ }^{*} \mathrm{O}$ porcentual foi calculado em função do número de respondentes. 
Para a seleção de empregados, o método preferido por praticamente todos os empresários era a entrevista pessoal $(76,6 \%)$, por meio da qual o empresário, baseado no seu feeling, escolhia a pessoa mais apropriada para a função que estava vaga. A seguir, os métodos de seleção mais utilizados por essas empresas eram referências $(66,7 \%)$, carteira profissional $(43,3 \%)$, testes práticos ou de conhecimentos gerais e específicos (16,6\%), e um período de 90 dias de experiência $(6,6 \%)$. De forma geral, os empresários se utilizavam de mais de um método.

\section{Treinamento}

Todas as empresas que participaram do estudo faziam treinamento interno, e $63,3 \%$ delas faziam tanto o interno como o externo. No treinamento interno, os novos empregados eram treinados, na maioria das vezes, pelo próprio dono do negócio, que lhes ensinava as rotinas operacionais, além de procedimentos próprios da empresa. A maioria das empresas que só fazia treinamento interno justificou sua resposta por considerar os cursos externos caros e não poder pagálos, ou por achar que não valia a pena investir no empregado, pois avaliava que, depois que os empregados aprendiam, eles deixavam a empresa. Entre as que só faziam treinamento interno (36,6\%), apenas uma das empresas adotava uma sistemática diferente das demais, pois contratou uma empresa privada para treinar seu pessoal em técnicas de relações humanas.

Cerca de $63,3 \%$ dos entrevistados faziam também treinamento externo, encaminhando seus empregados para cursos específicos em órgãos como SEBRAE e SENAC. Este estudo procurou identificar também as necessidades de treinamento, de modo que se apresentam, na Tabela 2, quais os cursos que os empresários gostariam que lhes fossem oferecidos.

Os entrevistados também foram solicitados a avaliar se a oferta de cursos, no Estado, era adequada, e também a opinar sobre a qualidade deles. Observouse que apenas $30 \%$ dos respondentes consideravam que a oferta atual atendia às suas necessidades; além disso, dois desses empresários foram muito críticos e avaliaram muito mal os cursos oferecidos, dizendo que o curso era muito teórico e não ia direto ao assunto, ou que não tinha qualidade e o professor era pior do que ele. Entre os $70 \%$ que consideraram que a oferta era insuficiente, muitos justificaram suas respostas dizendo que a oferta era limitada, que não existiam cursos no interior, que, de forma geral, os cursos eram fracos, e que os órgãos que ofereciam treinamento e o governo não atuavam eficientemente.
Tabela 2. Necessidades de treinamento

\begin{tabular}{|l|c|c|}
\hline Cursos & Freqüência absoluta* & Freqüência relativa** $^{* *}$ \\
\hline $\begin{array}{l}\text { Atendimento ao cliente/ relações } \\
\text { humanas/comunicação }\end{array}$ & 15 & 50,0 \\
\hline Camareira/governança & 7 & 23,3 \\
\hline Recepcionistas & 4 & 13,3 \\
\hline Informações turísticas sobre o Estado & 4 & 13,3 \\
\hline Boas maneiras/ postura & 3 & 10,0 \\
\hline Motivação & 3 & 10,0 \\
\hline Total de respostas & 36 & - \\
\hline Total de respondentes & 30 & 100,0 \\
\hline
\end{tabular}

A questão admitiu mais de uma resposta.

${ }^{*}$ O porcentual foi calculado em função do número de respondentes.

\section{Benefícios}

Praticamente todos os estabelecimentos hoteleiros de pequeno porte no Estado ofereciam refeições ou lanches para seus empregados. Estes, geralmente, tinham direito à refeição no horário em que estavam trabalhando, mas de forma geral, esta consistia praticamente no que sobrara ainda do café da manhã, pois muitas empresas não tinham restaurante para almoço ou jantar. Uma das empresas oferecia também, para o almoço, o ticket do SESC. Cerca de $66,6 \%$ ofereciam uniformes, mas apenas $6,6 \%$ possuíam plano de saúde ou odontológico. Foi mencionado que era sempre melhor selecionar empregados que morassem nas proximidades, para não terem de pagar o vale-transporte. Além dos benefícios mencionados, foram citados a cesta básica, a cesta de Natal e presentes.

\section{Rotatividade}

Apesar de a atividade hoteleira sofrer grande influência de fatores sazonais, cerca de $53,3 \%$ não consideravam a rotatividade de seus empregados um problema específico do setor. Para os que consideravam rotatividade um problema co- 
mum na hotelaria $(46,65)$, a lei trabalhista foi apontada como o maior empecilho, pois muitos empregadores avaliavam que o empregado queria receber o segurodesemprego e o FGTS, não permanecendo no emprego por muito tempo. Outros consideraram que as características típicas da própria atividade, tais como os horários noturnos e o trabalho nos finais de semana, eram as maiores responsáveis pela rotatividade.

\section{Profissionais que pretendem contratar}

Procurou-se identificar que tipo de profissionais as empresas pesquisadas pretendiam contratar. Observou-se que $50 \%$ não pretendiam realizar futuras contratações, pois não tinham condições de assumir maiores custos com salários e encargos (Tabela 3). A seguir foi mencionada por alguns a necessidade de profissionais para atuar em vendas, como gerentes, recepcionistas egovernantas. Para o cargo de gerente foi mencionado que seria contratada pessoa da família. Foi também citada a necessidade de contratação de pessoal para atuar na área de informática e de outros profissionais, como office-boy, camareira, copeira e auxiliar administrativo. Alguns citaram que irão utilizar mão-de-obra temporária e serviços terceirizados nos períodos de alta estação por causa dos altos encargos sociais. Um dos entrevistados admitiu que pretende demitir em vez de contratar.

Tabela 3. Tipo de profissional que pretende contratar

\begin{tabular}{|l|c|c|}
\hline Tipo & Freqüência absoluta* & Freqüência relativa** \\
\hline Não pretende contratar & 15 & 50,0 \\
\hline Profissional de vendar/MKT & 5 & 16,6 \\
\hline Gerente & 3 & 10,0 \\
\hline Recepcionistas & 2 & 6,6 \\
\hline Governantas & 2 & 6,6 \\
\hline Outros & 7 & 23,3 \\
\hline Total de respostas & 34 & - \\
\hline Total de respondentes & 30 & 100 \\
\hline
\end{tabular}

* A questão admitiu mais de uma resposta.

** O porcentual foi calculado em função do número de respondentes.

\section{Requisitos e/ou habilidades para a contratação}

Os entrevistados foram solicitados a avaliar quatro requisitos e/ou habilidades para a contratação de profissionais para suas empresas: escolaridade, aparência, experiência anterior e conhecimentos de língua estrangeira. Apesar de terem sido encontrados profissionais trabalhando nessas empresas sem sequer possuírem o primeiro grau, a grande maioria, $93,3 \%$ dos entrevistados, afirmou que exigiam o nível de escolaridade de primeiro ou segundo grau, dependendo da função a ser exercida. Para recepcionistas, dois empresários mencionaram que estavam procurando universitários, mas estes permaneciam por pouco tempo, pois os salários eram baixos. Cerca de 13,3\% informaram que não se importavam com o grau de escolaridade na hora de contratar seu pessoal, especialmente para as camareiras, os copeiros e os auxiliares de serviços gerais, sendo necessário apenas que soubessem fazer seu trabalho.

Com relação à aparência, foi destacada a sua importância para os profissionais que atuassem na recepção, principalmente, e à limpeza, para todos os demais. A experiência anterior foi considerada por $46,6 \%$ dos empresários entrevistados requisito absolutamente irrelevante, e afirmaram que preferem eles mesmos treinar seu pessoal, pois os que possuem experiência têm vícios de outro emprego. O conhecimento de línguas estrangeiras foi visto por $80 \%$ dos empresários de pequenos estabelecimentos como irrelevante, pois consideravam que não teriam como pagar salários mais altos para profissionais bilíngües. Alguns acharam que seria interessante que o pessoal da recepção tivesse noções básicas de inglês, enquanto outros disseram que isso não seria necessário.

\section{Maiores deficiências dos empregados}

Procurou-se identificar também quais as maiores deficiências dos empregados quanto às suas habilidades técnicas e comportamentais. Com relação a este aspecto, observou-se que os empresários percebiam a falta de noções de higiene e limpeza, o desconhecimento dos atrativos turísticos do Estado e a dificuldade de escrever como as principais deficiências técnicas entre os seus empregados. Entre as habilidades comportamentais destacaram-se a falta de iniciativa dos empregados, a falta de vontade de aprender coisas novas, a dificuldade de relacionamento, a displicência com o trabalho e a falta de educação básica, que, sem dúvida, é a origem das demais deficiências. 


\section{Profissionais difíceis de encontrar no mercado}

Metade dos empresários entrevistados informou que não tinha nenhuma dificuldade de encontrar profissionais no mercado de trabalho para trabalhar em sua empresa, pois, segundo eles, o desemprego no Estado era muito grande e havia gente demais procurando emprego. Alguns deles, no entanto, destacaram que o grande problema não era a carência de pessoas, mas a sua qualificação e atitude, pois acabavam querendo sair depois de seis meses por causa do seguro-desemprego. Para os demais 50\% havia a carência de alguns profissionais, destacando-se os recepcionistas (23\%) e cozinheiros (10\%), além de lavadeiras capazes de operar lavanderia industrial, pessoal administrativo para a área de custos, almoxarifado e copeiros. Para 13,3\% dos que responderam que havia carência, o que existia de fato era falta de pessoal qualificado, e não de pessoal em si.

\section{Contratação de graduados}

A maioria dos empresários dos pequenos estabelecimentos hoteleiros-66,7\% - não contrataria graduados para atuar em seu negócio por considerar que não teriam como pagá-los, pois o estabelecimento era pequeno ou a família assumia as funções gerenciais. Entre os que contratariam esses profissionais, mencionou-se a preferềncia por graduados em Administração, Turismo e Hotelaria. Perguntados sobre o salário que podiam pagar a esses graduados, os entrevistados apresentaram valores que se encontram na faixa entre dois e oito salários mínimos.

Dentre os conhecimentos técnicos considerados essenciais para esses profissionais graduados, destacaram todos os respondentes a necessidade de conhecimentos de marketing, informática, contabilidade/finanças e, em menor escala, inglês. Além desses foi mencionada também a importância de que tais profissionais possuíssem conhecimentos em hotelaria, relações humanas, eventos, ou soubessem um pouco de tudo e tivessem experiência prática em gerenciar. Entre as habilidades comportamentais necessárias para os graduados atuarem nessas empresas, foi enfatizada a necessidade de relacionamento interpessoal, liderança e comunicação oral.

\section{Contratação de estagiários}

Com exceção de duas empresas participantes do estudo, praticamente todos os entrevistados (93,3\%) afirmaram que contratariam estagiários em suas empresas. No entanto, foi visível a preferência por estagiários de cursos profissionalizantes oferecidos pelo SENAC, SEBRAE e Prefeitura, pelo Programa de Ação Solidária, e não os oriundos de cursos de nível superior. Alguns afirmaram que gostariam de contratar universitários, mas não tinham como pagá-los, pois o negócio era pequeno.

\section{Maiores desafios}

Perguntados a respeito dos maiores desafios com pessoal que tinham de enfrentar, os empresários/gerentes destacaram a falta de qualificação e de escolaridade, que impedia que os empregados assimilassem novos conhecimentos (Tabela 4). A seguir, percebeu-se como desafio para os empresários/gerentes a falta de motivação, o interesse no trabalho e a ausência de iniciativa dos empregados. A existência de "fofoca" entre os empregados e as dificuldades no relacionamento entre eles, assim como a legislação trabalhista que estimulava o empregado a sair por causa do seguro-desemprego também foram mencionados. Apenas 10\% dos empregadores comentaram que não tinham preocupações quanto ao futuro, porque, geralmente, a mão-de-obra atendia às necessidades da empresa e, de forma geral, o pessoal era honesto e trabalhador.

Entre as principais carências percebidas pelos empresários com relação às habilidades e/ou competências necessárias para o desempenho das funções, observou-se que estas foram divididas em duas categorias: operacionais e comportamentais. Dentre as carências na parte operacional, destacaram-se: dificuldade de comunicação oral no atendimento ao hóspede e ao telefone; dificuldade para escrever em virtude da baixa escolaridade; ausência de noções de higiene; falta de prática na atividade hoteleira; e desconhecimento dos atrativos turísticos e da própria cidade. Já na parte comportamental, as principais carências encontraram-se relacionadas à falta de educação doméstica, pois sendo os empregados, de

Tabela 4. Principais desafios

\begin{tabular}{|l|c|c|}
\hline Problemas & Freqüência absoluta & Freqüência relativa \\
\hline Falta de qualificação/escolaridade & 13 & 43.3 \\
\hline Acomodação/falta de iniciativa/motivação & 7 & 23.3 \\
\hline Relacionamento & 6 & 20.0 \\
\hline Legislação trabalhista & 2 & 6.6 \\
\hline Não tem preocupações & 3 & 10.0 \\
\hline Total & 30 & 100 \\
\hline
\end{tabular}


forma geral, pessoas rudes e oriundas de famílias muito pobres, sentiam dificuldades para assimilar novos conceitos de qualidade e de atendimento ao cliente.

\section{Conclusões e considerações finais}

De acordo com a World Travel and Tourism Council - wTTC (2003), de forma geral, o grande desafio a ser enfrentado pelo setor turístico mundial, que cresce $4,5 \%$ ao ano, é o abastecimento dos postos de trabalho com mão-de-obra qualificada. Outros dois grandes problemas que envolvem a mão-de-obra turística são a alta rotatividade de empregados e a falta de atrativos dos postos de trabalho, que não conferem status aos ocupantes nem plano de carreira definido, os salários são baixos, os horários muitas vezes inconvenientes, faltando condições para que a empresa mantenha uma equipe estável e de alto nível. Esses problemas e desafios só poderão ser devidamente equacionados quando a gestão de pessoas nas empresas de pequeno porte deixar de ser apenas relacionada ao controle de funções burocráticas e legais, para se tornar efetivamente atividade de gestão, assumida de forma profissional pelos proprietários ou gerentes.

No entanto, pode-se constatar que essa situação não é encontrada apenas no Brasil, pois, quando se compararam os resultados desse estudo com os encontrados por Nickson (1999) no Reino Unido, observou-se que eles em muito se assemelhavam, quando tal autor afirmou que as práticas de gestão de pessoas em empresas hoteleiras podiam ser vistas naquele país como insatisfatórias. De fato, quando se observaram os processos de recrutamento, seleção, treinamento e os demais aspectos da gestão de pessoas adotados pelas empresas de pequeno porte do setor hoteleiro em Sergipe, verificou-se que essas práticas eram informais e que não havia visível interesse por parte dos seus empresários em modificá-las ou aprimorá-las. Porém, quando se analisaram os resultados do presente estudo sob a perspectiva do argumento apresentado por Baum (1999), que enfatizou a necessidade do Estado de apoiar a capacitação de pessoas nas empresas de pequeno porte, observou-se que, em Sergipe, essa participação era indiscutivelmente insignificante. Observou-se, ainda, que a avaliação pelos empresários da qualidade e da quantidade do treinamento oferecido pelos órgãos no Estadoé muito crítica, poiseles consideravam que não apenas na capital, mas principalmente no interior, a oferta era insuficiente, e os cursos, muito teóricos.

Quanto aos salários pagos no setor hoteleiro, pode-se constatar que são evidentemente muito baixos, mas quando comparados a outros estudos realizados em pequenas empresas do setor industrial (Teixeira \& Barbosa, 2002), observou-se que essa também é a realidade nos demais setores no Estado. No entanto, é preciso estar consciente das implicações negativas que esses baixos salários podem trazer, principalmente para a qualidade dos serviços na hotelaria, que é basicamente dependente das pessoas.

Outro aspecto que se destaca nos resultados é o descrédito dos órgãos/ agências que ofertam treinamento por sua dificuldade em atender especificamente às necessidades das pequenas empresas do setor, ou em oferecer aos empresários do ramo os conhecimentos que eles consideram relevantes para a condução dos seus negócios. Vale destacar, também, que as perspectivas quanto à contratação de pessoal nessas empresas são limitadas, e o quadro ainda é mais crítico quando se refere à contratação de graduados, pois os cargos gerenciais encontram-se geralmente ocupados por familiares, ou a empresa não tem como absorver profissionais que demandem salários mais altos.

Entretanto, a baixa escolaridade dos empregados pode ser destacada como o maior desafio da gestão de pessoas nas empresas de pequeno porte do setor hoteleiro em Sergipe, pois essa limitação se reflete em todos os demais aspectos, a exemplo das dificuldades dos empregados em absorver novos conhecimentos e melhorar a qualidade dos serviços prestados. Esse fato também está diretamente ligado à produtividade e ao desempenho individual no trabalho, ou seja, indivíduos mais educados e capacitados produzem mais e melhor, por isso são mais bem remunerados. Como conseqüência direta ocorre a desmotivação e o desinteresse pelo trabalho, que os empresários percebem como um dos seus principais problemas de pessoal. Aumentar o nível de educação das pessoas que atuam ou poderão atuar do setor seria o primeiro passo para uma mudança da forma de gerenciar esses recursos, vitais para o desenvolvimento das pequenas empresas.

Finalmente, sugere-se quefuturos estudos sejam efetuados, buscando-se identificar as melhores práticas de gestão de pessoas em empresas de pequeno porte do setor hoteleiro, de sorte que também possam servir de benchmarking para as outras empresas do ramo. Recomenda-se, ainda, a realização de estudos voltados para a identificação das necessidades de qualificação da mão-de-obra para o setor, os quais possam servir de subsídios para o planejamento de ações destinadas às peculiaridades do setor hoteleiro e à oferta de programas de educação profissional voltados para o turismo.

\section{Referências bibliográficas}

ANASTASSOVA, L. \& PURCEL, K. 1995. Human resource management in the Bulgarian hotel industry: from command to empowerment? International Journal of Hospitality Management, v. 14, n. 2 .

AQUINO, C. A. B. 1994. Atraçāo de recursos humanos para o preenchimento do quadro funcional de pequenas e médias empresas hoteleiras da cidade de Fortaleza. Dissertaçāo (Mestrado em Administraçāo) - Universidade Federal da Paraíba, Joāo Pessoa. 
ARAÚJO, M. M.; MENDES, N. M. M. \& ENDERS, W. T. 1982. Avaliação dos recursos humanos no setor turístico de Natal: uma análise na percepção dos turistas. In: ENCONIRO DA ASSOCIAÇĀO NACIONAL de programas de pós-graduaÇão em administração, 6, 1982, Sạlvador. Anais... Salvador: eña.jpaì. ARBACHE, J. S. 2003. O mercado de trabalho na atividade econômica do turismo no Brasil. Centro de Excelência em Turismo (CET), Universidade de Brasília: Itamarati, 2003.

BARBOSA, A. C. Q. 1991. A problemática dos conflitos em micro e pequenas unidades produtivas. In: ENCONTRO Da ASSOCIAÇÃO NACIONAL. DE PROGRAMAS DE PÓS-GRADUAÇÃO EM ADMINISTRAÇĀO, 15, 1991, Belo Horizonte. Anais... Belo Horizonte: ENANPAD.

BARBOSA, M. L. A. \& OLIVEIRA, L. M. B. 2002. O marketing interno como estratégia de gerenciamento dos recursos humanos em hotéis: um estudo de caso na região metropolitana do Recife. Revista Organizaçōes e Sociedade, Salvador: ЕaufBA, v. 9, n. 24 maio/agosto.

BAUM, T. 1999. Human resource management in tourism's small business sector: policy. In: LEE-ROS (Ed.). Tourism and hospitality: international perspectives on small to medium-sized enterprises. London: Cassel. p 3-16.

BOHLANDER, G.; SNELL, S. \& SHERMAN, A. 2003. Administraçāo de recursos humanos. São Paulo: Pioneira.

CHENG, A. \& BROWN, A. 1998. HRM strategies and labour turnover in the hotel industry: a comparative study of Australia and Singapore. The International Journal of Human Resource Management, v. 9. n. 1, Feb.

COLLIN, A. 2001. In: BEARDWELL, I \& HOLDEN, L. (Coords.). Human resource management. 3. ed. Edinburgh: Pearson Education Limited.

DIAS, E. L. 2000. A Importância do capital humano na indústria do turismo. In: ENCONTRO DA ASSOCIAÇÃO NAGIONAL DE PROGRAMAS DE PÓS-GRADUAÇĀO EM ADMINISTRAÇĀO, 24,2000, Florianópolis, Anais... ENANPAD. DUARTE, V.V. A. 1996. Administração de sistemas hoteleiros: conceitos básicos. São Paulo: SENAC. EAGLEN, A.; LASHELY, C. \& THOMAS, R. 1999. Benefits and costs analysis: the impact on business performance. The Hospitality Training Foundation: Leeds Metropolitan University.

GUEIROS, M. G. \& OLIVEIRA, L. M. B. 1998. Qualidade de vida no trabalho: um estudo no setor de hotelaria na região metropolitana do Recife. In: KNOWLES, T. Hospitality management: an introduction. 2. ed. Harlow: Longman.

LAGE, B. H. G. \& MILONE, P. C. (Orgs.). 2000. Turismo: teoria e prática. São Paulo: Atlas.

LIMA, Juvêncio Braga. 2000. Temas de pesquisa e desafios da produção científica sobre PME. Revista de Estudos Organizacionais. Maringá: DAD/CSA/UEM, v. 1, n. 2, jul./dez.

LONGENECKER, J. G.; MOORE, C. W. \& PETTY, J. W. 1997. Administração de pequenas empresas. São Paulo: Makron Books.

McGUNNIGLE, P. J. \& JAMESON, S. 2000. HRM in UK hotels: a focus on commitment. Employees Relations, v. 22. n. 4.

NICKSON, P. D. 1999. Human resource management in hotel accommodation services. In: VERGINNIS, C. \& WOOD, R. New direction in accommodation managementfor the hotel industry. London: ITBS.

PAIM, D. C. T. et al. 2001. Estratégias de gestão de recursos humanos em empresas de agronegócio do planalto médio do Rio Grande do Sul: um estudo multicaso. In: EGEPE - ENCON- tro de ESTUdOS SObRe EMPREENDEDORISMO E GESTÃo DE PEQUENAS EMPRESAS, 2, 2001, Londrina. Anais.. Londrina: UEı/UEM, p. 324-336.

PIZOLOTTO, M. F. 2003. A Gestão de pessoas: um estudo em micro e pequenas empresas da indústria de transformação da Região do Médio-Alto-Uruguai do Rio Grande do Sul. In: EGEPE - EGEPE - ENCONTRO DE ESTUdOS SObRE EMPREENDEDORISMO E GESTÃo DE PEQUENAS EMPRESAS, 3, 2003, Brasília. Anais... Brasília: UNB/UEı/UEM.

PLANO de Desenvolvimento Integrado do Turismo Sustentável para o Pólo Costa dos Coqueirais (PDITS). 2002. SEPLANTEC-SE/ PRODETUR-NE II, Aracaju.

REIS, A. P. \& ESCRIVÃO FILHO, E. 2003. Análise das barreiras à prática do treinamento na pequena empresa. In: ENCONTRO DA ASSOCIAÇÃO NACIONAL DE PROGRAMAS DE PÓS-GRADUAÇÃO EM ADMinISTRAÇĀo, 27, 2003, Atibaia. Anais... Atibaia: ENANPAD.

SEBRAE. 1993. Indicadores de competitividade para micro e pequenas empresas industriais no Brasil. Projeto SEBRAE/UfRJ-IEI, Brasília.

SEBRAE. Balcão SEBRAE on line. Disponível em: <http://www.se.sebrae.com.br/Eventos/ estatuto.htm>. Acesso em: 10 jun. 2003.

SILVA, A. L. J. \& BARBOSA, M. L. A. 2002. O treinamento como ferramenta para padronização dos serviços em uma empresa hoteleira. In: ENCONTRO DA ASSOCIAÇĀO NACIONAL. DE PROGRAMAS DE POS-GRADUACC̄̃ EM ADMINISTRAC̄ĀO, 26, 2002, Salvador. Anais... Salvador: ENANPAD.

TEIXEIRA, R. M. 1996. Small business and social responsibility in Brazil. 344 f. Tese (Doutorado em Administração) - Cranfield School of Management, Cranfield University, Inglaterra

TEIXEIRA, Rivanda Meira \& BARBOSA, Jenny Dantas. 2002. People management in small and medium industries". In: Balas 2002. Conference, 2002, Tampa. Annals... Tampa: Balas.

TEIXEIRA, Rivanda Meira; ANDRADE JÚNIOR Alexandre L. \& BANGANGA, Sebastião. F. 1998. Recursos humanos nas pequenas empresas: um enfoque dos anos 90. In: ENCONTRO DA ASSOCIAÇÃO NACIONAL DE PROGRAMAS DE PÓS-GRADUAÇão EM ADMINISTRAÇĀO, 22, 1998, Foz do Iguaçu. Anais... Foz de Iguaçu: ENANPAD.

THOMAS, et al. 2000. The national survey of small tourism and hospitality firms: 2000 - skill demands and training practices. Report of Centre for the Study of Small Tourism and Hospitality Firms: Leeds Metropolitan University.

UDENAL, L. \& GIMENEZ, F. A. P. 2001. Criatividade e recursos humanos na pequena empreSa". In: EGEPE - ENCONTRO DE ESTUDOS SOBRE EMPREENDEDORISMO E GESTÃO DE PEQUENAS EMPRESAS, 2 , 2001, Londrina. Anais... Londrina: UEl//UEM, p. 324-336.

WORLD TOURISM ORGANISATION - wTO. 2000. Marketing tourism destinations. wro Business Council, sept.

WRIGHT, L. T. 1996. Exploring the in-depth interview as a qualitative research technique with American and Japanese firms. Marketing Intelligence and Planning, v. 14, n. 6, p. 59-64.

WTTC. Corporate social leadership in travel and tourism. Disponível em: $<$ http://www.wttc.org/>. Acesso em: 12 jan. 2003.

Recebido em: 22/11/2004

Aprovado em: 13/05/2005 
Relacionadas à parte técnica operacional

Relacionadas à parte comportamental:

9. O sr. contrataria um graduado para trabalhar no seu hotel?

Sim ( ) Que formação?

Não ( )

Explique sua resposta (ver agora/ no futuro).

Caso positivo, qual o salário que poderia pagar?

10. Que tipo de conhecimento técnico esse profissional deveria possuir? (classifique por ordem de importância).

Informática ( )

Marketing ( )

Finanças ( )

Contabilidade ( )

Inglês ( )

Outros:

11. Que tipo de habilidade/competência ele deveria possuir? (por ordem de importância). Experiência anterior do tipo de negócio ( )

Relacionamento interpessoal (empregado/cliente) ( )

Liderança ( )

Boa comunicação oral ( )

Outras:

12. A sua empresa abriria espaço para que os alunos fizessem estágio prático?

$\operatorname{Sim}(\quad)$

Não ( ) Explique

13. Como faz a seleção dos seus empregados?

Referências ( )

Entrevista ( )

Carteira de Trabalho ( )

Teste de conhecimento ( )

Outros ( ) Especifique:
14. Como faz o treinamento do seu pessoal?

Internamente ( ) Por quê?

Externamente ( ) Por quê?

15. De que tipo de treinamento o sr. acha que seus empregados estão precisando para melhorar o desempenho?

16. Existe oferta suficiente de cursos (treinamento) no mercado para atender às suas necessidades?

Sim ( ) Que instituiçōes oferecem?

Não ( )

Explique:

17. Oferece algum beneficio além do vale-transporte?

Plano de saúde ( )

Refeiçōes ( ) Quais?

Uniforme ( )

18. Falando de rotatividade, quantas pessoas, em média, o sr. contrata por ano? Quantas demite?

19. O sr. considera que a rotatividade dos empregados é um problema nesse setor de atividade?

20. Quais são os maiores problemas de pessoal que o sr. tem?

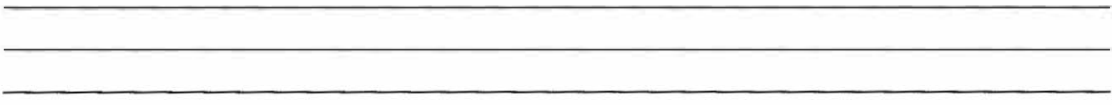

21. Quais são as maiores deficiências da mão-de-obra que trabalha na atividade hoteleira?

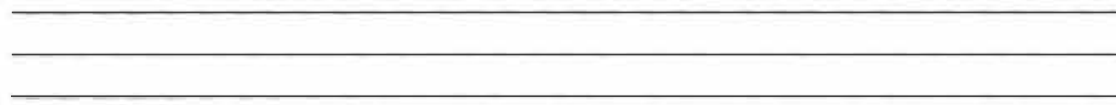

